\title{
Missing coronary artery Review of technical problems in coronary arteriography resulting from anatomical variants
}

\author{
R M DONALDSON, M J RAPHAEL \\ From National Heart Hospital, Cardiothoracic Institute, and Middlesex Hospital, London
}

SUMMARY In $75(0.9 \%)$ of 8235 patients without associated congenital heart disease studied by $\overrightarrow{.}$ arteriography, a vessel was missing from its normal location, and this was the result of an anomalous $N$ origin. Symptoms attributable to these aberrant vessels were present in 19 of the 75 patients. 은 Though rare, these anomalies can produce specific clinicopathological entities which can be diag- $\vec{c}$ nosed angiographically and treated surgically. Failure to recognise these anomalies of coronary anatomy prolonged arteriographic procedures and led to repeated catheterisations in 28 of the $75 \frac{\mathrm{g}}{2}$ cases $(37 \%)$.

Coronary arteriography is routinely used as a diagnostic measure or as a prelude to surgical treatment. Failure to visualise a coronary artery division is relatively frequent and generally attributable to a complete proximal occlusion, even if no stump of blocked artery is demonstrated. Failure to intubate a coronary artery is usually the result of inadequate technique. Both of these failures may be caused by congenital variants of anatomy with which the investigator should be familiar.

In this paper we survey and illustrate the congenital variations of the coronary arteries which were documented in 75 out of 8235 patients without associated congenital heart disease, discuss their incidence in the routine investigation of patients with suspected ischaemic heart disease, and suggest a methodical approach to their recognition.

\section{Patients and methods}

Major anatomical variations of the coronary circulation were documented in 75 of 8235 patients $(0.9 \%)$ who underwent coronary arteriography for suspicion or exclusion of coronary artery disease at the National Heart and Chest Hospitals and The Middlesex Hospital over a seven year period ending December 1980. Patients' data are shown in Table 1; those with associated congenital heart disease were excluded.

Their ages were 16 to 66 years (mean 44$)$ at the time

Accepted for publication 18 September 1981 of angiography; 51 were male and 24 female. Symp-toms attributable to the aberrant vessel were present? in 19 of the $75(25 \%)$. Sixteen patients had angina, eight of them with dyspnoea on exertion; in additiong two presented with episodes of palpitation caused by⿳亠口冋 ventricular tachyarrhythmias and one further patient was investigated because of unexplained episodes of exertional dyspnoea and syncope. The aberrant origin and course of the coronary arteries was diagnosed by angiography alone in 63 patients. A clinical diagnosis

Table 1 Patient data (75 patients out of 8235 undergoing coronary angiography)

Symptoms attributable to aberrant vessel

Angina

Angina and dyspnoea

Palpitation

Unexplained exertional dyspnoea and syncope

Anomalies leading to symptoms

Left anterior descending from pulmonary artery

Left coronary artery from anterior sinus

Left coronary artery from pulmonary artery

Stenosis in aberrant vessel

Electrocardiogram

Ischaemic ST-T changes

Infarction ( $Q$ waves)

Normal

Associated findings at catheterisation

Atherosclerotic occlusive disease

(Stenosis in aberrant vessel

Valvular disease

Akinetic or aneurysmal wall motion

Congenital absence of left pericardium

Coarctation

No evidence of heart disease 
of anomalous origin of the left coronary artery from the pulmonary artery was made in the remaining 12 patients who presented in adult life with the classical features of this anomaly. Electrocardiography suggested myocardial ischaemia in 28 patients and transmural myocardial infarction in 15; in 10 of the latter the necrosis was caused by the retrograde flow in the left coronary artery.

Investigations showed no other evidence of heart disease in 16 patients, atherosclerotic coronary occlusive disease in 33, and valvular heart disease in 12 (congenital bicuspid aortic valve in three, rheumatic carditis in nine). Twelve additional patients had angiographic evidence of infarction (akinetic or aneurysmal wall motion) and two more had associated congenital abnormalities (coarctation of the aorta and congenital absence of the left pericardium). Coronary arteriography was performed in all cases using either the Sones or the Judkins technique. In 28 of the 75 cases $(37 \%)$ the procedure was repeated because of inadequate visualisation of the aberrant vessel. Fifteen patients were reinvestigated once, nine twice, three three times, and one on four occasions before a correct diagnosis could be made.

\section{Arteriographic findings}

The apparently missing coronary artery at arteriography could be analysed under four groups (Table 2).

\section{(1) MISSING ANTERIOR DESCENDING CORONARY} ARTERY

Failure to visualise the anterior descending branch of the left coronary artery in the normal location usually occurred when the anterior descending and circumflex divisions had independent aortic origins in the left sinus of Valsalva, an anomaly encountered in eight patients.

More rarely the anterior descending coronary artery emerged from the right sinus of Valsalva, either independently or jointly with the right coronary artery (Fig. 1); this variant was found in four patients.

Finally, in two patients the anterior descending coronary artery originated from the pulmonary artery. The angiographic appearances were characteristic, the left main stem leading directly to a dilated circumflex division only and after a short delay, and a very large vessel in the position of the anterior descending opacifying, from which contrast streamed into the main pulmonary artery (Fig. 2). This aberrant

\section{Table 2 Angiographic findings}

\begin{tabular}{|c|c|}
\hline Variants of coronary anatomy & $\begin{array}{l}\text { No. of } \\
\text { patients }\end{array}$ \\
\hline $\begin{array}{l}\text { (1) Missing left anterior descending ( } L A D) \\
\text { (a) Separate origin } L A D \text { and } L C x \text { in left } \\
\text { sinus of Valsalva } \\
\text { (b) Origin LAD from right sinus of Valsalva } \\
\text { or from RCA } \\
\text { (c) LAD from PA }\end{array}$ & $\begin{array}{l}8 \\
4 \\
2\end{array}$ \\
\hline $\begin{array}{l}\text { (2) Missing left circumflex artery ( } L C x \text { ) } \\
\text { (a) Separate origin LAD and LCx in left } \\
\text { sinus of Valsalva (as la) } \\
\text { (b) Origin LCx from right sinus of Valsalva } \\
\text { or RCA }\end{array}$ & $\begin{array}{l}8 \\
26\end{array}$ \\
\hline $\begin{array}{l}\text { (3) Missing right coronary artery (RCA) } \\
\text { (a) RCA and LCA from left sinus of Valsalva (2) } \\
\text { RCA from LCA (1) } \\
\text { Extreme left dominance (4) } \\
\text { (b) Separate origin RCA and long conus artery }\end{array}$ & 7 \\
\hline $\begin{array}{l}\text { (4) Missing left coronary artery ( } L C A) \\
\text { (a) LCA from right sinus of Valsalva } \\
\text { (b) LCA from RCA } \\
\text { (c) LCA from PA }\end{array}$ & $\begin{array}{l}2 \\
1 \\
13\end{array}$ \\
\hline
\end{tabular}
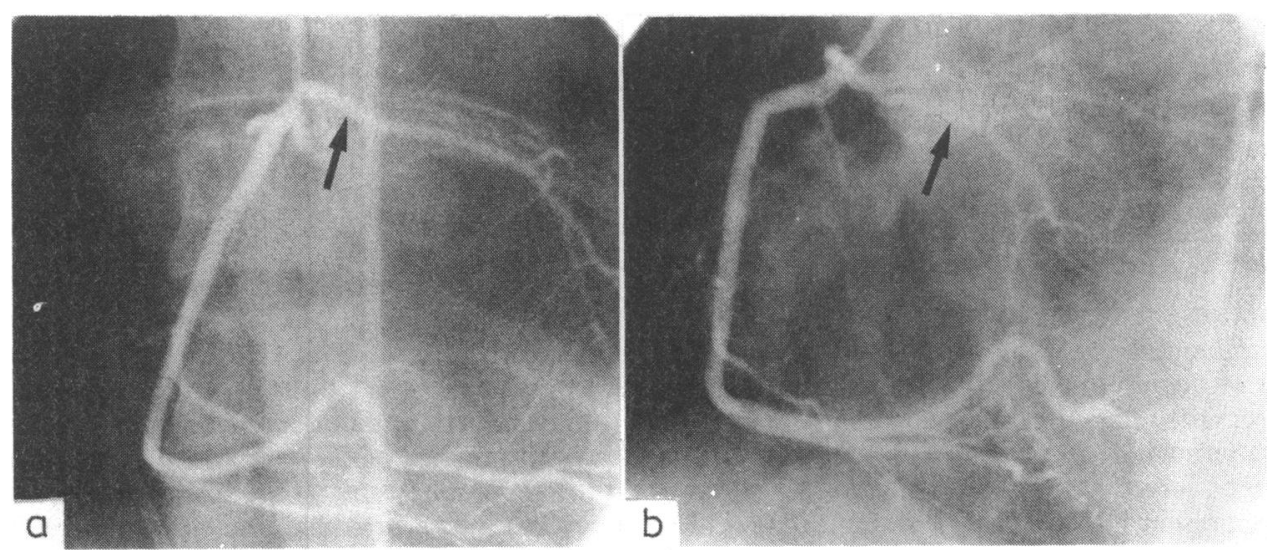

Fig. 1 Origin of the left anterior descending from the right sinus of Valsalva (joint ostium with right coronary artery). (a) Anteroposterior view; (b) left anterior oblique projection. Arrow indicates the aberrant left anterior descending coromary artery. 

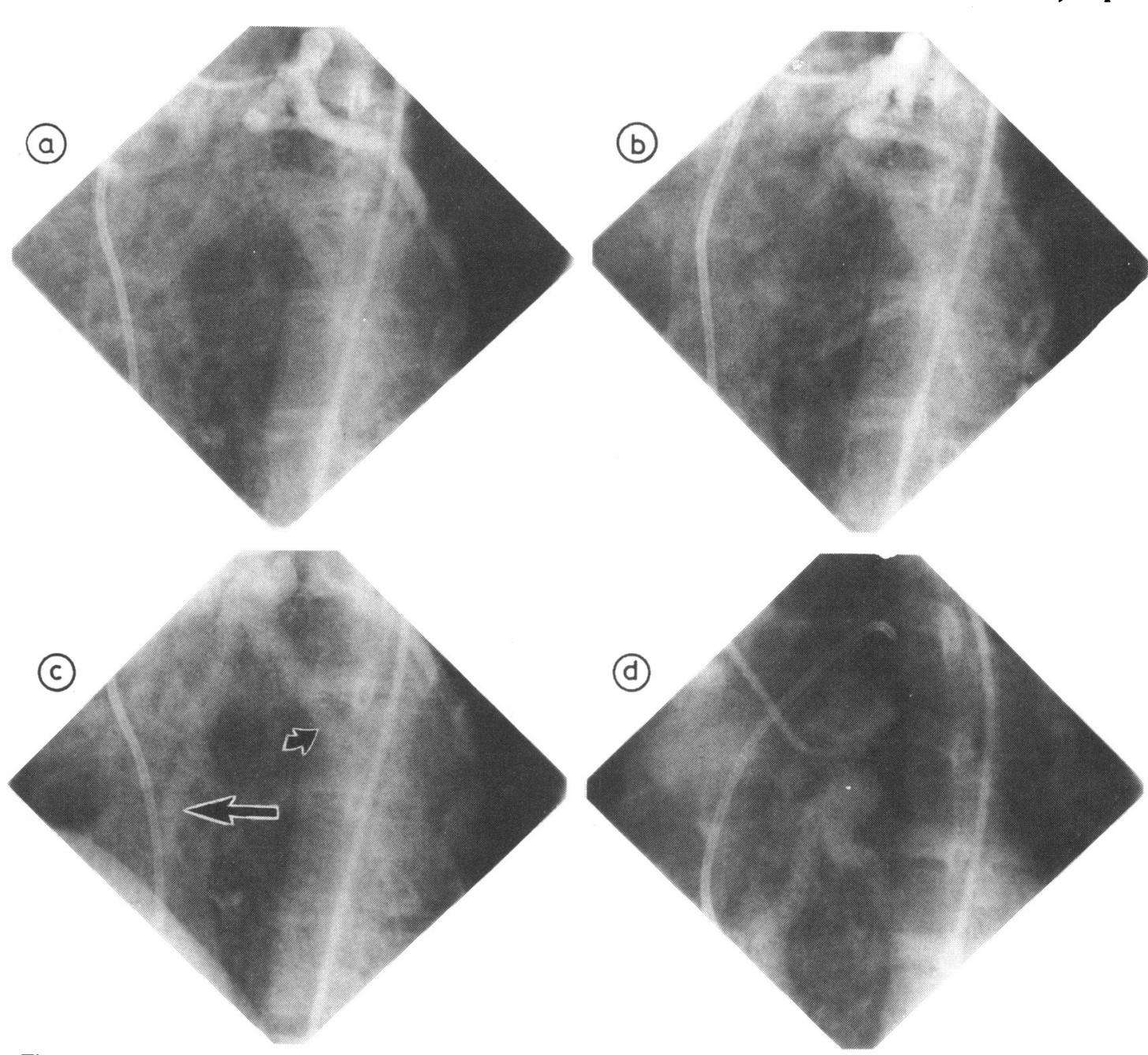

Fig. 2 Abnormal origin of the left anterior descending coronary artery from the pulmonary artery. (a) and (b) Lefi coronary injection, lefi anterior oblique projection. Early arterial phase, showing a large circumflex coronary artery. Note the lefi anterior descending coronary artery fails to opacify. (c) Late phase, showing delayed filling of the dilated left anterior descending coronary artery (large arrow) and diagonal (small arrow) through collaterals. (d) Contrast medium streaming into the main pulmonary artery.

anterior descending vessel also filled when the right coronary artery was injected

\section{(2) MISSING LEFT CIRCUMFLEX ARTERY}

The commonest variant leading to an apparent absence of the circumflex was when this vessel originated from the right coronary artery either as a branch of the latter or independently from a separate ostium in the right coronary sinus (Fig. 3 and 4). This variation was present in 26 of the 75 patients (35\%). The abnormal circumflex usually travelled around the back of the aorta to the left atrioventricular groove and then pursued its normal course over the free wall of the left ventricle. Apparent absence of the left circumflex artery was also noted in the eight patients with separate origins of the anterior descending and circumflex arteries in the left sinus of Valsalva.

(3) MISSING RIGHT CORONARY ARTERY

In seven cases no right coronary ostium or artery was $\mathbb{\complement}$ present. In two of these the ostium originated from $\stackrel{?}{+}$ the left coronary sinus (Fig. 5) and in a third the right $\frac{}{T}$ coronary was a proximal branch of the left. In these cases the right coronary travelled to the right and $\stackrel{\odot}{\circ}$ anteriorly, between the aorta and right ventricular ${ }^{\circ}$ infundibulum, to reach its usual anatomical location. 


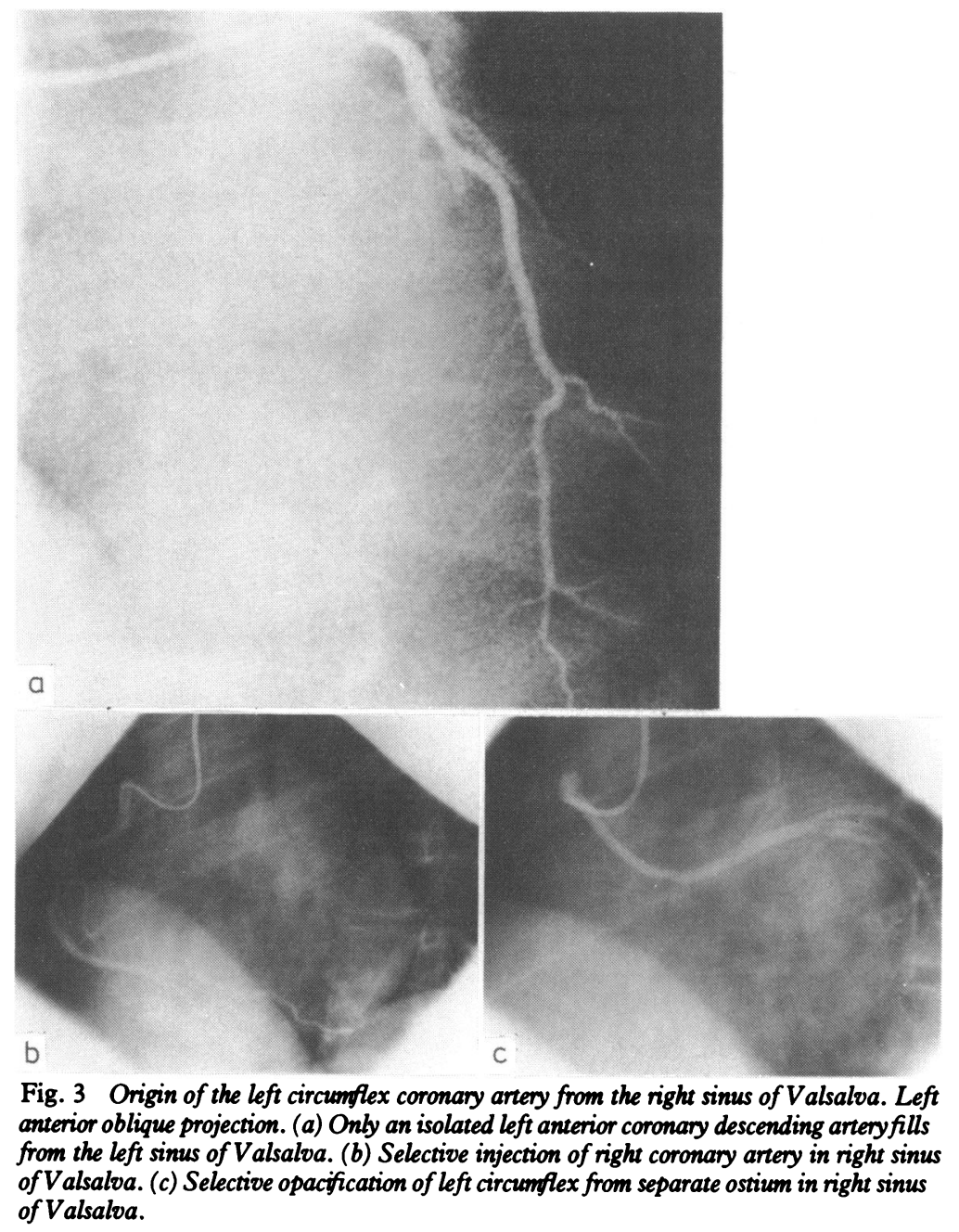

In the other four patients the right coronary artery was entirely replaced by a large circumflex which continued round the heart to reach the right atrioventricular groove to supply the right ventricular branches (extreme left dominance) (Fig. 6).

A right ventricular branch or the conus artery may be selectively catheterised either as a proximal branch of the right coronary or when either of these have an independent ostium (Fig. 7). There were 12 patients who had a separate origin of a long, low branching conus artery which followed an anterior course in front of the right ventricular outflow tract to reach the lateral surface of the heart.

(4) MISSING LEFT CORONARY ARTERY

There were three patients in whom the left coronary artery originated in the right aortic sinus (Fig. 8); one of these had a common ostium for both the left and right coronary arteries. From this abnormal ostium, the left main coronary artery then curved to the left and posteriorly, running intramurally inside the aortic wall, between the aorta and the right ventricular infundibulum to reach the left coronary sinus. From that point onwards the left coronary artery had a normal course and distribution behind the pulmonary artery. These patients all had ischaemic symptoms though their coronary arteries were free of atheroma.

In 13 cases the left coronary artery was a branch of the pulmonary artery. The right coronary artery filled from the aorta and was grossly dilated; after a shorter delay, the left coronary artery opacified via extensive collaterals and the contrast was seen streaming into the main pulmonary artery. Selective right coronary arteriography indicated associated stenosis in two 


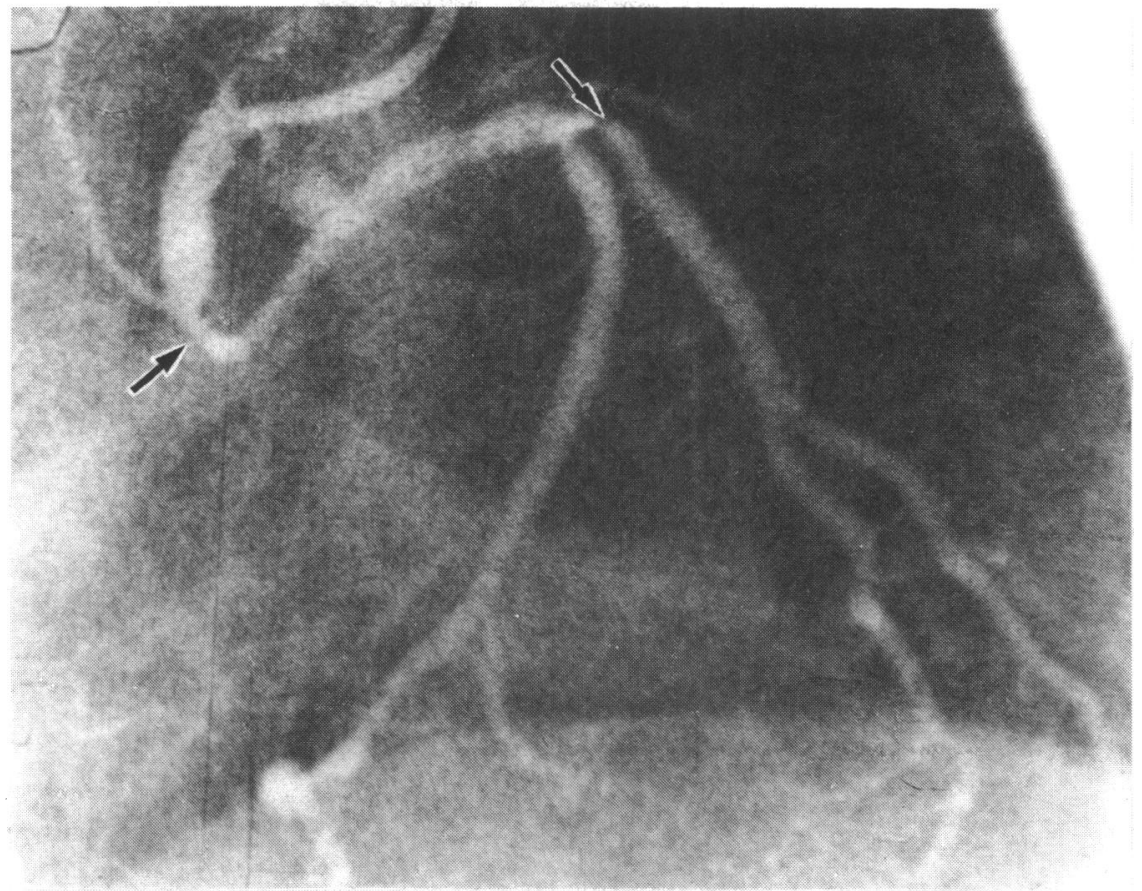

Fig. 4 Abnormal origin of the left circunflex from the right sinus of Valsalva. The aberrant vessel has significant atherosclerotic narrowing (arrows).
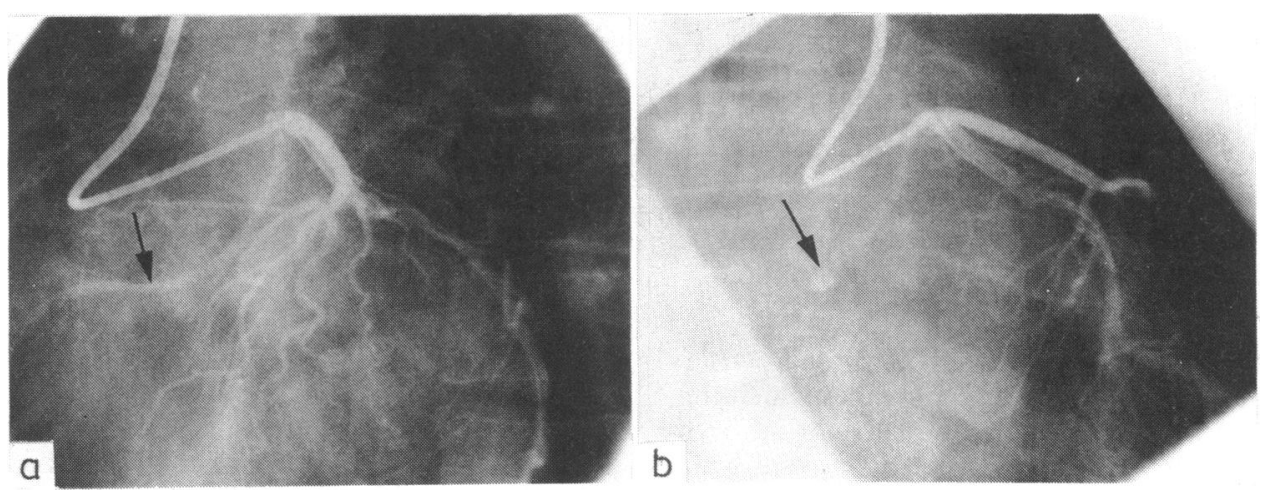

Fig. 5 Origin of the right coronary artery from the left sinus of $V$ alsalva, jointly with the left coronary artery. (a) Left anterior oblique and (b) right anterior oblique projection. The aberrant right coronary artery is arrowed.

patients with this anomaly who had undergone previous surgical attempted ligation of the aberrant vessel.

\section{Surgery}

Surgical confirmation of the angiographic diagnosis was obtained in 41 patients; 14 of these underwent surgery for an anomalous vessel which produced significant abnormalities of myocardial perfusion, with relief of the presenting symptoms. These $\widetilde{\sigma}$ patients can be divided into three major groups: (1) two had the anterior descending branch of the left coronary artery arising from the pulmonary artery treated by ligation and vein grafting; (2) two had the left coronary artery arising from the anterior sinus and both underwent successful anatomical correction; (3) ten had the left coronary artery arising from the pulmonary artery, all with reversal of flow and left to 

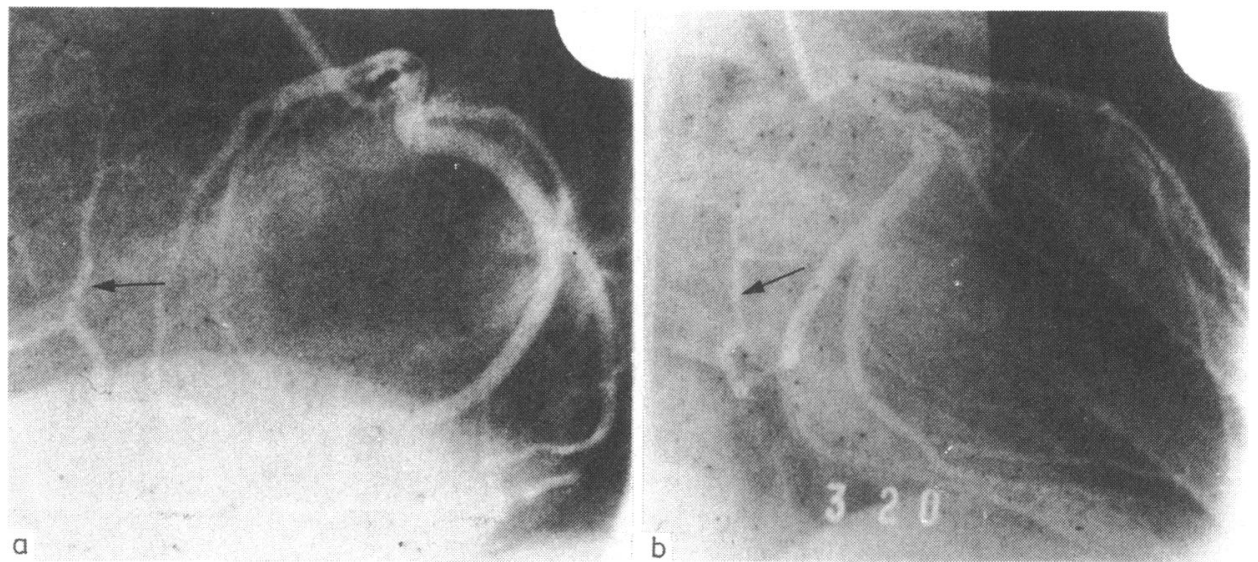

Fig. 6 Extreme left dominance. Selective injection of left coronary artery. (a) Lateral and (b) right anterior oblique projection. The left circumflex continues around the heart in the right atrioventricular groove to replace the right coronary artery (arrowed).
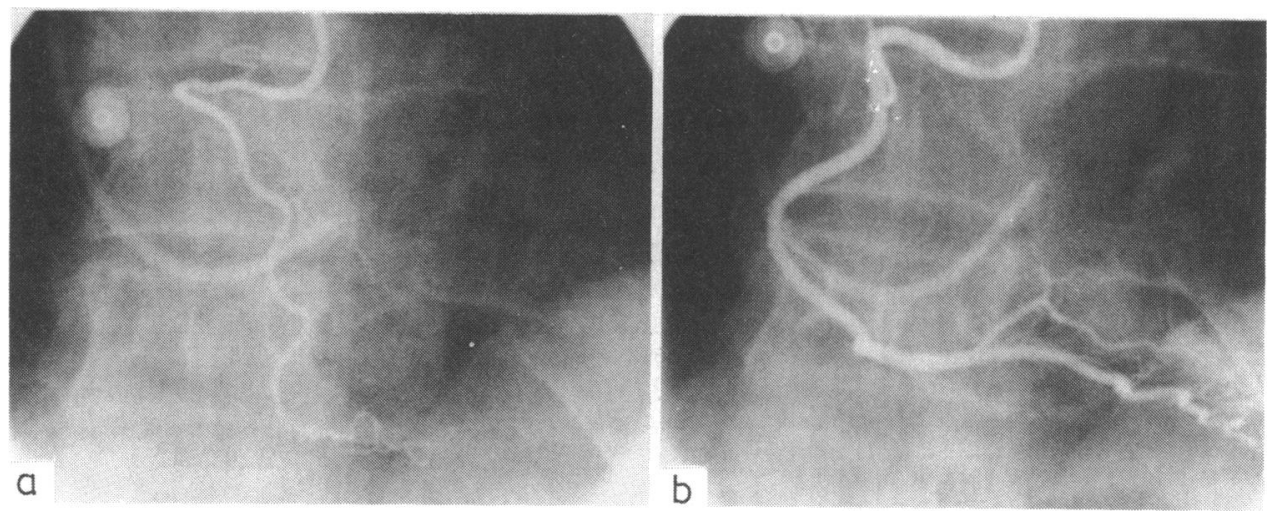

Fig. 7 Separate origin of the right coronary artery and long right ventricular branch. (a) Selective right ventricular branch injection; (b) the main right coronary artery is opacified.

right shunting; anatomical correction was performed in five and other methods of revascularisation with either vein grafts or an antologous left subclavian artery segment were used in the other five patients.

A further five patients underwent coronary surgery for narrowing or occlusion of a major aberrant vessel.

\section{Discussion}

The demonstration of anatomical changes in the coronary arteries has become important in patient management but visualisation of all coronary arteries is not always achieved. This, however, is usually because of imperfect technique. In a small proportion of patients one or more arteries have an atypical origin and these morphological variants may lead to difficulties in the performance or interpretation of the coronary arteriograms. It is possible that these aberrant vessels are not as rare as published reviews suggest. ${ }^{1-3}$ As most of them are not associated with physiological upset, they show no typical clinical picture and are detected only by careful arteriographic technique. The incidence in our series was only $0.9 \%$, but in this retrospective study cases were included only if the anomalous vessel was adequately filled on the arteriogram. In many cases with suspected aberrant vessels the examination was inadequate and these patients were excluded from further analysis.

It has become increasingly evident that some of these aberrant vessels can be associated with a variety of syndromes, from angina pectoris to sudden death. ${ }^{4-7}$ Symptoms predominantly of exertional angina and attributable to the aberrant vessel were present in $19(25 \%)$ of the 75 cases in our series $(0.2 \%$ of the whole). A further 33 (44\%) of the 75 patients had angina attributable to significant coronary artery 

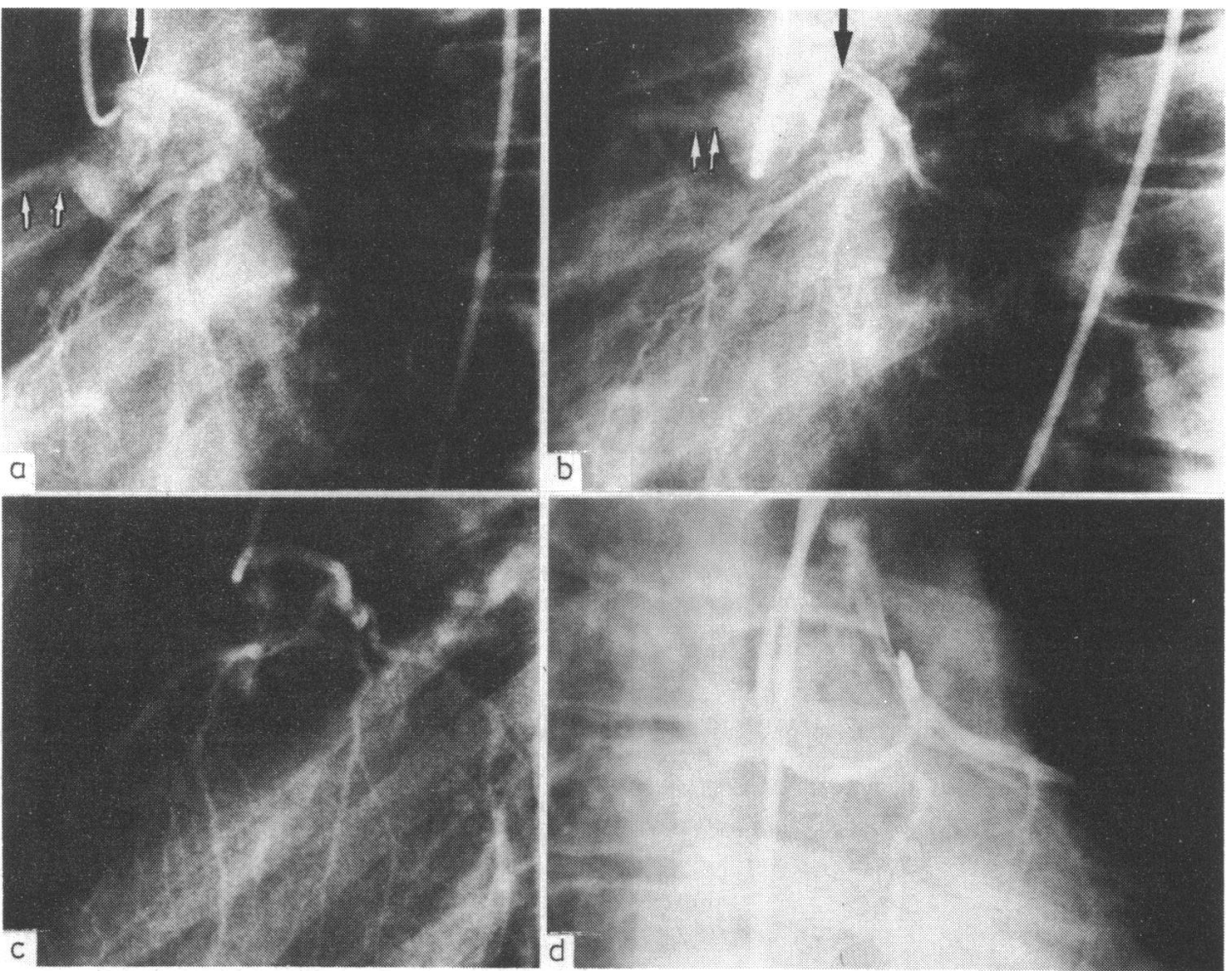

Fig. 8 Origin of the left coronary artery from the right sinus of Valsalva. Selective left coronary injection. (a) and (b) Left anterior oblique views. The normal right coronary ostium (small arrows) is seen in profile. The ostium of the left coronary artery is clearly anterior (large arrows). (c) Lateral view. Note the posterior course of the left main stem which when normal appears end-on in this view. (d) Right anterior oblique view. Catheter filling the left coronary artery is lying in the anterior sinus of Valsalva.

disease; of these, eight had narrowing or occlusion in the aberrant vessel (Fig. 4).

Failure to visualise a coronary artery should alert the operator to the possibility of an aberrant vessel, as coronary arteries rarely disappear when diseased and a blocked vessel almost invariably fills distally by collateral flow, except in the presence of aneurysm. ${ }^{8}$ The first problem is to recognise that opacification is incomplete and most difficulty occurs with the branches of the left coronary artery. It is important to check that the left coronary artery gives both anterior descending and circumflex branches before accepting that opacification is complete. The true lateral view is important where there is doubt. ${ }^{9}$

\section{(1) ABSENT LEFT CORONARY BRANCHES}

If only the anterior descending fills when the catheter enters an artery in the left sinus of Valsalva, the most frequent origin of the circumflex is either as a proximal branch of the right coronary artery or from a separate ostium in the right sinus of Valsalva (Fig. 3) and this area should be explored. If, however, the catheter enters only the circumflex from the left sinus of Valsalva the most likely site of origin of the anterior descending is from the same (left) sinus and its ostium is usually near to that of the circumflex. Only rarely does the anterior descending originate from the right coronary artery or right sinus of Valsalva (Fig. 1). These anatomical variants can lead to technically difficult studies but they generally have little importance in the absence of atherosclerotic narrowing in the aberrant vessel. ${ }^{10}$ When the abnormal circumflex originates from the right sinus of Valsalva, however, and follows a retroaortic course, it may inadvertently be damaged during mitral valve surgery, ${ }^{11}$ with consequent myocardial infarction.

With a short left main stem the catheter may go selectively into one or other division; this should be apparent if the contrast is injected fast enough to reflux into the sinus of Valsalva, when both branches will be visualised.

In two patients who presented with angina in adult 
life the anterior descending originated from the pulmonary artery (Fig. 2). The diagnosis could easily be missed as the demonstration of two coronary ostia arising from the aorta, with very large and tortuous arteries, may suggest a form of coronary fistula, rather than the possibility of an anomalous artery with a third ostium in the pulmonary trunk. This anomaly, though rare, is important as symptoms may be relieved by ligation or grafting of the aberrant vessel. ${ }^{12}$

\section{(2) ABSENT RIGHT CORONARY ARTERY}

Although difficulty in intubating the right coronary artery is not rare, probing the right sinus of Valsalva with test injections will usually succeed in locating the ostium. If this fails, the investigator should review the appearances of the left coronary artery to check that the right is not a branch of the left, either proximal (from the main stem or left coronary sinus) or terminal (Fig. 5 and 6). This condition, though of morphological interest, appears to have a fairly benign clinical course. ${ }^{13}$

The origin of the right coronary artery from the pulmonary artery is rare and relatively benign, ${ }^{14}$ and we did not encounter this anomaly.

The conus branch of the right coronary artery can be a source of technical difficulty during attempts to visualise the right coronary artery if the catheter goes selectively into it. The investigator must be alert to this possibility by keeping in mind the relative balance between the circumflex and the right coronary arteries. The clinical importance of this lies in the fact that the main right coronary may not be opacified and contrast injection into the conus branch may precipitate arrhythmias. Furthermore, the conus branch may be a major source of collateral circulation in the presence of occlusive disease. ${ }^{15}$

\section{(3) ABSENT LEFT CORONARY ARTERY}

Even in adult patients, the commonest reason for failing to find the ostium of the left main coronary artery in its usual site in the left sinus of Valsalva was when it arose from the pulmonary artery (13 of the 16 cases). This did not present a problem as in the majority the diagnosis was obvious clinically. The origin of the left coronary artery from the pulmonary artery is rare but of.great physiological and clinical importance since it produces symptoms, is diagnosable during life, and is surgically treatable. ${ }^{16-18}$ The few patients who survive infancy and later in life present with angina and evidence of ischaemia but no signs of necrosis of the left ventricle have a better prognosis than those showing the classical clinical picture. ${ }^{19}$

In the remaining three patients in whom the left coronary ostium was not in its normal position, the left coronary artery originated from the right (anterior) aortic sinus (jointly with the right coronary artery in one case), just in front of the intercoronary commissure (Fig. 8). This sinus should therefore be carefully explored when there is difficulty in finding the left coronary artery in its normal location, as this anomalous origin may cause symptoms resulting from myocardial ischaemia and may even lead to sudden death at a young age..$^{20-23}$ In most of the patients reported there has been a history of exertional angina or syncope (as in the three patients in our series), together with anatomical or functional obstruction of this aberrant left coronary, most probably caused by acute angulation of the ostium and compression of the intramural segment. Because of the grave prognosis, coronary surgery should be considered in young symptomatic patients with this anomalous origin of the left coronary artery. ${ }^{13} 24$

That a coronary artery is apparently missing is of considerable importance to both patient and investigator. Some anomalies may produce specific clinicopathological entities; equally as important, failure to recognise them may lead to inadequate and prolonged procedures. In $38 \%$ of our patients with coronary anomalies catheterisation had to be repeated, in one patient four times, to elucidate the problem before a correct diagnosis and curative surgery could be performed. Similarly, several patients had protracted catheterisation for apparent failure to intubate arteries which had already been opacified in an unexpected way.

\section{References}

1 Ogden JA. Congenital anomalies of the coronary arteries. Am f Cardiol 1970; 25: 474-9.

2 Liberthson RR, Dinsmore RE, Bharati S, et al. Aberrant coronary artery origin from the aorta: diagnosis and clinical significance. Circulation 1974; 50: 774-9.

3 Levin DC, Fellows KE, Abrams HL. Hemodynamically significant primary anomalies of the coronary arteries. Angiographic aspects. Circulation 1978; 58: 25-34.

4 Pachinger OM, Vandenhoven P, Judkins MP. Single coronary artery-a cause of angina pectoris. Eur $\mathcal{F}$ Cardiol 1974; 2: 161-5.

5 Chaitman BR, Lespérance J, Saltiel J, Bourassa MG. Clinical, angiographic, and hemodynamic findings in patients with anomalous origin of the coronary arteries. Circulation 1976; 53: 122-31.

6 Newton MC Jr, Burwell LR. Single coronary artery with myocardial infarction and mitral regurgitation. $\mathrm{Am}$ Heart F 1978; 95: 126-7.

7 Kimbiris D, Iskandrian AS, Segal BL, Bemis CE. Anomalous aortic origin of coronary arteries. Circulation 1978; 58: 606-15.

8 Paulin S, Schlossmann D. Coronary angiography: technique and normal anatomy. Critical Reviews in Clinical Radiology and Nuclear Medicine 1973; 4: 333-400. 
9 Raphael MJ, Hawtin DR, Allwork SP. The angiographic anatomy of the coronary arteries. Br $\mathcal{F}$ Surg 1980; 67: 181-7.

10 Page HL Jr, Engel HJ, Campbell WB, Thomas CS Jr. Anomalous origin of the left circumflex coronary artery: recognition, angiographic demonstration and clinical significance. Circulation 1974; 50: 768-73.

11 Roberts WC, Morrow AG. Compression of anomalous left circumflex coronary arteries by prosthetic valve fixation rings. F Thorac Cardiovasc Surg 1969; 57: 834-8.

12 Donaldson RM, Thornton A, Raphael MJ, Sturridge MF, Emanuel RW. Anomalous origin of the left anterior descending coronary artery from the pulmonary trunk. Eur F Cardiol 1979; 10, 295-300.

13 Liberthson RR, Dinsmore RE, Fallon JT. Aberrant coronary artery origin from the aorta. Report of 18 patients, review of literature and delineation of natural history and management. Circulation 1979; 59: 748-54.

14 Wald, S, Stonecipher K, Baldwin BJ, Nutter DO. Anomalous origin of the right coronary artery from the pulmonary artery. Am $\mathcal{F}$ Cardiol 1971; 27: 677-81.

15 Levin DC, Beckmann CF, Garnic JD, Carey P, Bettmann MA. Frequency and clinical significance of failure to visualize the conus artery during coronary arteriography. Circulation 1981; 63: 838-47.

16 Wesselhoeft H, Fawcett JS, Johnson AL. Anomalous origin of the left coronary artery from the pulmonary trunk. Its clinical spectrum, pathology and pathophysiology based on a review of 140 cases with seven further cases. Circulation 1968; 38: 403-25.

17 El-Said GM, Ruzyllo W, Williams RL, et al. Early and late results of saphenous vein graft for anomalous origin of left coronary artery from pulmonary artery. Circulation 1973; 48, suppl III: 2-6.

18 Neches WH, Mathews RA, Park SC, et al. Anomalous $\overrightarrow{\overrightarrow{\mathrm{C}}}$ origin of the left coronary artery from the pulmonary artery. A new method of surgical repair. Circulation 1974; 50: 582-7.

19 Wilson CL, Dlabal PW, Holeyfield RW, Akins CW, $\frac{\bar{\rho}}{\bar{D}}$ Knauf DG. Anomalous origin of left coronary artery $\unrhd$ from pulmonary artery. Case report and review of literature concerning teenagers and adults. $\mathcal{F}$ Thorac Cardiovasc Surg 1977; 73: 887-93.

20 Jokl E, McClellan JT, Williams WC, Gouze FS, Barth- $\overrightarrow{-}$ olomew RD. Congenital anomaly of the left coronary artery in young athletes. Cardiologia (Basel) 1966; 49: 253-8.

21 Cohen LS, Shaw LD. Fatal myocardial infarction in an 11 year old boy associated with a unique coronary artery.anomaly. Am f Cardiol 1967; 19: 420-3.

22 Benson PA, Lack AR. Anomalous aortic origin of left coronary artery: report of two cases. Arch Pathol 1968; 86: 214-6.

23 Cheitlin MD, DeCastro CM, McAllister HA. Sudden

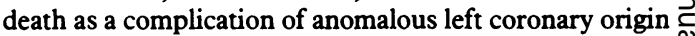
from the anterior sinus of Valsalva. A not-so-minor congenital anomaly. Circulation 1974; 50: 780-7.

24 Moodie DS, Gill C, Loop FD, Sheldon WC. Anomalous $\underset{\infty}{\mathscr{C}}$ left main coronary artery originating from the right sinus of Valsalva. F Thorac Cardiovasc Surg 1980; 80: 198205.

Requests for reprints to Dr R M Donaldson, National Heart Hospital, Westmoreland Street, London W1M 8BA. 